\title{
DETERMINATION AND ANALYSIS OF ENERGY EFFICIENCY Potential in Socks Manufacturing System
}

\author{
Milovan Medojevic, Milana Medojevic, Ilija Cosic, \\ Milovan Lazarevic \& Dusanka Dakic
}
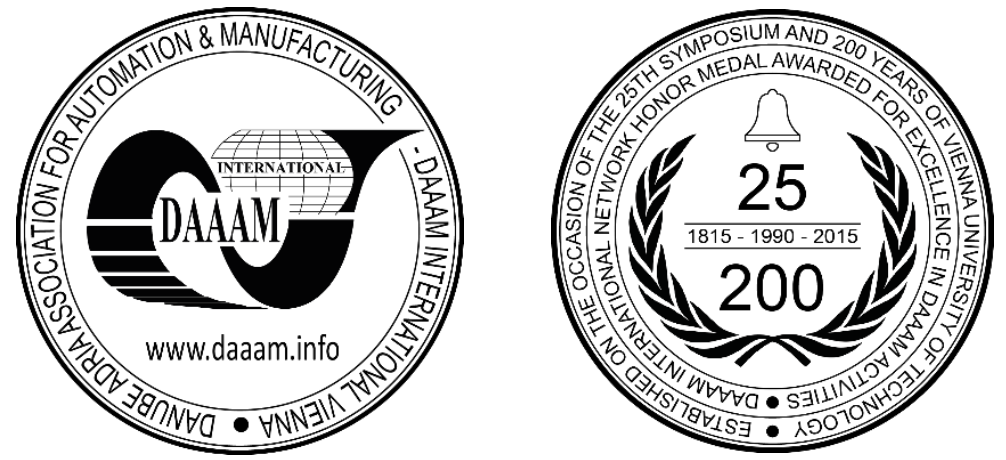

This Publication has to be referred as: Medojevic, M[ilovan]; Medojevic, M[ilana]; Cosic, I[lija]; Lazarevic, M[ilovan] \& Dakic, D[usanka] (2017). Determination and Analysis of Energy Efficiency Potential in Socks Manufacturing System, Proceedings of the 28th DAAAM International Symposium, pp.0582-0591, B. Katalinic (Ed.), Published by DAAAM International, ISBN 978-3-902734-11-2, ISSN 1726-9679, Vienna, Austria DOI: $10.2507 / 28$ th.daaam.proceedings.082

\begin{abstract}
In this study a systematic approach for determination and analysis of energy efficiency potential in socks manufacturing system was applied in order stimulate rational energy consumption. Moreover, an overview of socks manufacturing process was provided upon which significant energy uses in form of systems/processes/operation were identified. Although, all significant energy users should have appropriate energy sub-meters which can then be simply used to quantify the consumption of each use, in reality, few or none of energy uses are sub-metered, indicating that their consumption should be estimated. Consequently, a variety of models and statistical methods which can be used to describe energy use in manufacturing systems were recognized, while a general multivariable regression method for measuring industrial energy efficiency potential that takes into account changes in weather and production volume as major drivers of energy use in majority of manufacturing systems was applied in order to reveal opportunities for improving productivity through energy efficiency.
\end{abstract}

Keywords: Energy efficiency; Socks manufacturing; Multivariable regression

\section{Introduction}

It is generally known that textile industry is among the most complicated manufacturing industries mainly because it is a fragmented and heterogeneous sector dominated by small and medium enterprises (SMEs). However, characterizing the textile manufacturing industry is complex because of the wide variety of substrates, processes, machinery and components used, as well as finishing steps undertaken, where different types of fibres or yarns, methods of fabric production and finishing processes (preparation, printing, dyeing, chemical/mechanical finishing, and coating) all interrelate in producing a finished product [1].

On the other hand, it was confirmed by numerous studies and research projects, summarized by Hasanbeigi \& Price [1] that energy is one of the main cost factors in the textile industry. Dealing with energy issues is complex due to the fact that majority of energy forms are intangible or insensitive most times, while always representing the ability to perform 
work. Having this in mind, determination of energy efficiency of a system or process is an essential step towards the control of the energy consumption and energy costs.

Consequently, research on industrial energy use and energy efficiency potential in various manufacturing sectors [2-6], as well as analysis concerning definition and determination of energy efficiency potential pertaining to a process [7-11], led to divulgation of variety energy efficiency indicators, such as thermal efficiency, specific energy consumption, energy intensity index, etc.

Here, the most widely used indicator in industry is the specific energy consumption (SEC) of a given output (or input) [7], in which case despite the simple definition, several complicating factors arise in its implementation [7-11], such as:

- Complex manufacturing facilities with multi production lines;

- Variety of products distinguished by their energy intensity factor;

- Relevant variables that affect energy efficiency and consumption;

- Suitability for SEC indicator application;

- Unlike thermal efficiency, the SEC indicator lacks information on whether energy is used efficiently;

- Definition of suitable system boundaries to ensure that all energy users are considered equally and precisely.

Moreover, majority of textile manufacturing companies still lack appropriate methods to effectively address energy consumption in a comprehensive and practical manner [11].

Although seemingly obvious, energy savings represent energy that is not used. However, it is quite complicated to measure them directly, except in some cases, such as a straightforward energy conversion process where savings are calculated from improvement of the ratio between measured output and input [12]. Having this in mind, this paper is based on a systematic approach with aim to highlight the methods and analysis which foster energy efficiency prioritization on the example of one socks manufacturing system.

\section{Overview of socks manufacturing process}

Sock manufacturing is intensive and widespread branch of textile industry. Socks of various types and designs can be produced by using cotton, acrylic, polyester, and nylon yarns of different counts, quality and shades. In general, socks manufacturing process could be divided into five steps. The process begins with knitting, then seaming, wet finish, board pairing and packaging respectively.

Knitting is the basic section from where the production of the socks starts. Here, the high tech circular knitting machines use a series of knitting needles in a cylinder formation. The yarn is fed to the needles row after row through the stands, where horizontal rows are called courses, while the vertical rows of stitches are called wales. The knitting section follows the size specifications and yarn description provided by the sampling section. Maintaining the quality of the socks is parallel activity of the knitting section controlled by the quality manager of the factory. The knitting section works according to a shift wise schedule and issues the production to both, batch section and greige store. The production which is to be batched immediately is sent to batching section and production which is to be batched later is directed to the greige store.

After the socks are knit, the toe seams must be closed. In order to achieve this, socks move to the next operation known as seaming. Once it leaves the knitting section and after its first quality inspection, the socks are funnel to the seaming area. Here the toe opening is closed. Although there are many ways to seam a sock, the selection is often based on two factors. These factors are the quality of the seam itself and the comfort specified by the wearer. Subsequently, the fibers and the sock's intended use are considered to determine the appropriate seaming process upon which seaming operators align the socks in the machine for seaming. The socks are usually placed inside out for the process where the seam will be sown. In addition, extra fabric must be removed for a comfortable toe seam, after which the machine turns the sock right side out as the final step.

Once seaming is completed, the work items now look like socks and they are ready for the next step which is Wet Finish Process. Wet finish process can involve several operations where some of them are common for all socks, while specific socks acquire additional operations and treatment. In addition, socks are washed and dried after the knitting and seaming due to many reasons. Washing removes knitting oils and residue from yarns. It allows adding softeners and conditioners to soften them. Also, drying helps certain fibres to adapt for further treatments and ensures bulk increase to some socks depending on given requirements. The cleaning, conditioning, and softening products and amounts used vary depending on the type of socks where, the temperature of the water and drying are important drivers in providing the optimum quality. Wet Finish area also includes dyeing, scouring, and bleaching operations. Socks that are to be white are either bleached or scoured. Bleaching is an oxidizing process that removes colour from a sock, leaving it white. On the other hand, scouring is a soap bath that removes tints and impurities. Lastly, coloured socks are either dyed after knitting or knit with previously dyed yarn. Already dyed yarn is also known as in-grain yarn. By the use of in-grain yarns, many attractive colour blends and combinations are possible.

After the Wet Finish, socks are ready for the next step which is Boarding and Pairing. This process consists of three sub processes: boarding, pairing, and comprehensive quality check. During boarding process, the socks are pulled on a flat metal foot forms. The forms represent the desired shape and size of the socks. Then, the forms are steam pressed 
between two heated surfaces in order to shape the sock final appearance. Thereafter, the freshly boarded socks are paired. Having in mind that even socks knit with the same yarns, same machines and under the same settings vary slightly they must be adequately paired before they proceed to next operation. Therefore, pairing process matches socks with the same size variation. The Board/Pair operation is the last phase in the socks manufacturing. Quality issues that are found in this process are traced back through the manufacturing procedure to the source, documented, and corrected. Once the socks are boarded and paired, the next step is packaging. The paired socks are either sent to the packaging line for immediate shipment or to fulfil future orders. In practice, packaging is driven by requirements of customers.

Above mentioned processes and operations represent the basic activities in the socks manufacturing. However, manufacturing process may vary depending on variety of factors, such as materials used, available equipment, specific requirements from customers, etc. Therefore, for the purpose of this study, socks manufacturing process given in the form of block diagram shown in the figure 1 was a subjected to further analysis. Even though the analysis could be deeper and more complex it stimulates logical identification for potential optimization spots, system effectiveness and process energy efficiency improvements [13].

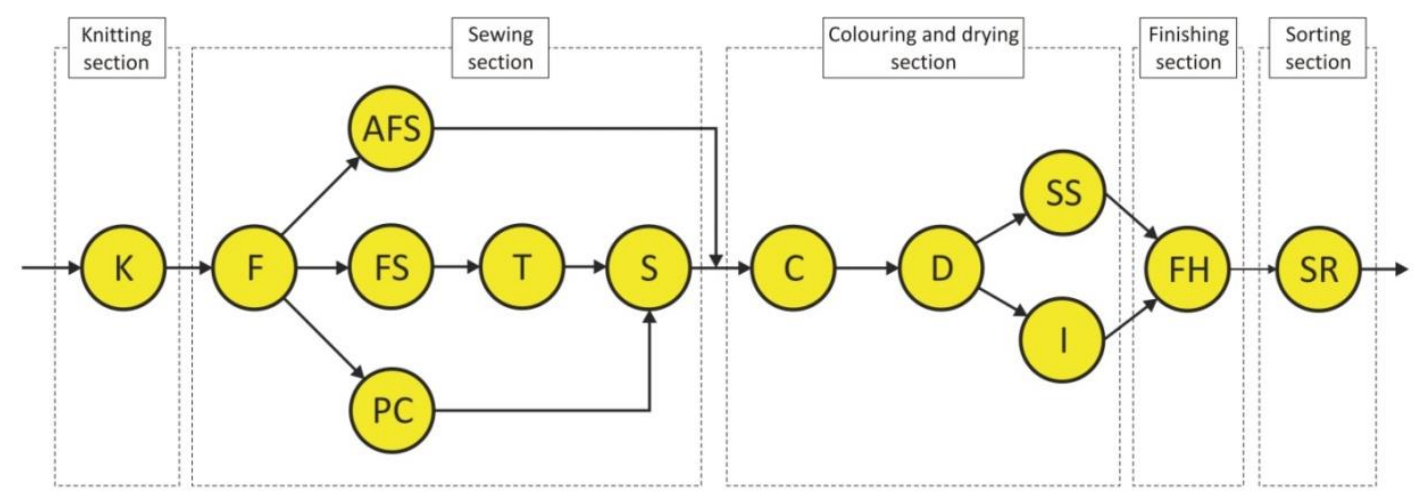

Fig. 1. Socks manufacturing operations flow diagram by relevant sections

In order to better understand the position of the operations identified by the process flow diagram (Fig. 1), they are shown on the factory layout given in the figure 2 .

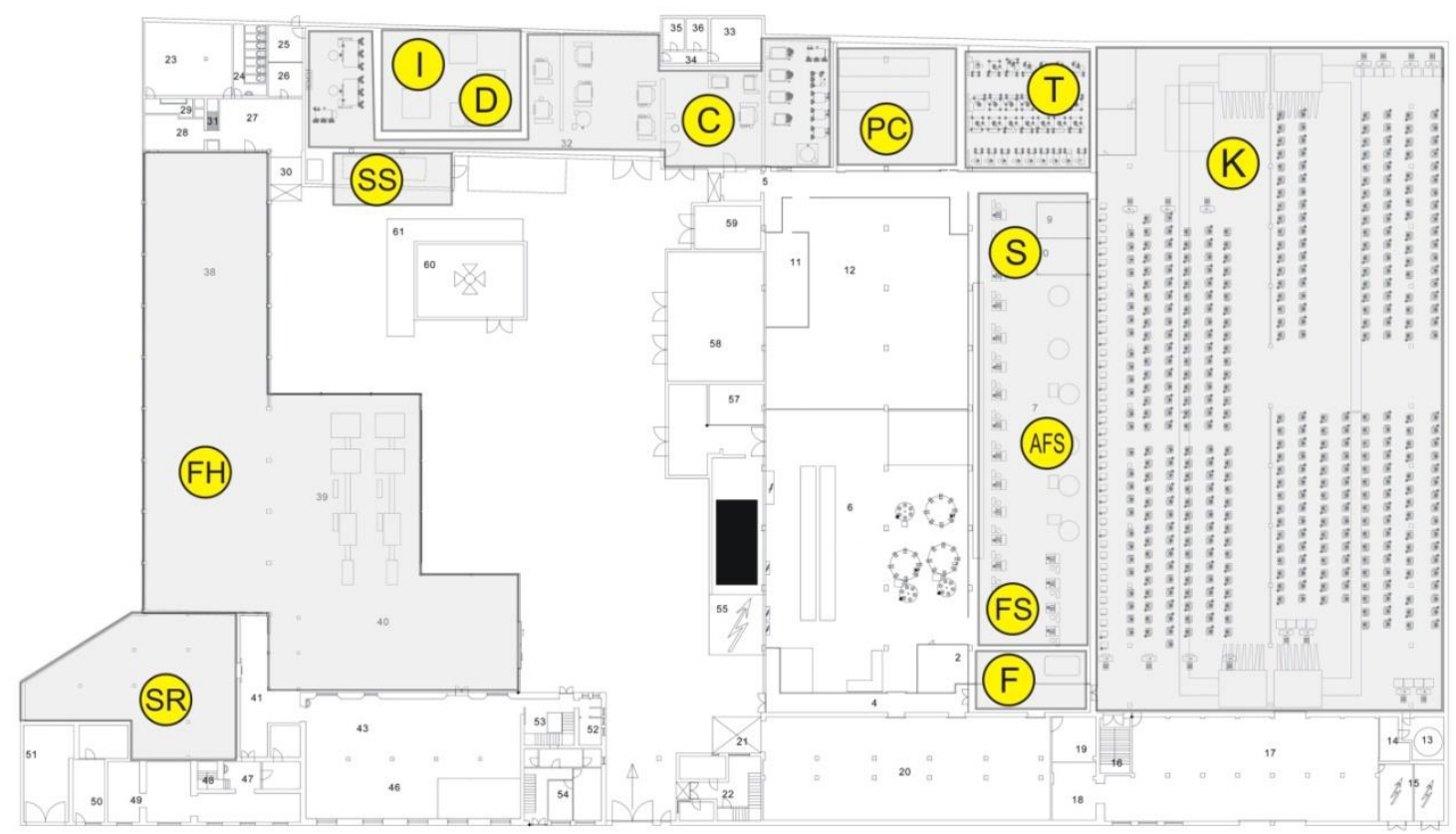

Fig. 2. Factory layout with the position of operations

Here the process starts form knitting (K), after which the socks are directed to Fixing machine (F) in order to improve the quality of socks and pads by thermal treatment. Afterwards, work items (pads and socks) continue to Fingers Sewing/Seaming (FS), Pad Cutting (PC) and Automated Fingers Sewing and sock fusing (AFS). PC is performed according to previously adopted specification (saddle, small, large, etc.) and after quality check pads are forwarded to sewing operation (S) where they are being attached to socks and sent for colouring (C). Simultaneously, AFS operation is fully automated and upon its completion work items are directly sent to C. Bearing in mind that FS differs from AFS, the tailoring operation (T) is introduced in order to perform sock cutting and altering. After T, this group of work items 
is sent to $\mathrm{S}$ and then to $\mathrm{C}$. Colouring machines are divided into two basic groups. The first group consists of machines in which the fleet is stationary and work items move (these machines are used to paint thicker socks), while the second group consists of machines in which the work items are stationary and the fleet moves (On these machines more demanding items are coloured, such as liquor, compression, stretch, etc.). After C, it is necessary to dry coloured work items in the drying machines associated to drying operation (D). Some of dried socks are then directed to sock shaping (SS) in order to form a final shape of wrinkled socks by exposing them to microwaves, while others (for which SS is not necessary) are forwarded to steam and electric ironing (I). Thereafter, formed socks are subjected to quality control for scrap elimination and packaging in the finishing operation (FH). Lastly, socks which have passed quality check are being sorted (SR) according to the specification.

Due to the variety and complexity of the processes involved in the socks manufacturing process, there are too many operations to be explained. Therefore, brief descriptions of the major processes and operations relevant from the energy consumption point of view are considered hereafter.

\section{Energy in the socks manufacturing}

In the observed manufacturing process, large quantities of both electricity and fuels are used. More precisely, in knitting, seaming and sewing processes electricity is being used by variety of machines in order to perform desired work, as well as to produce compressed air which is necessary for the machines operation. Moreover, electricity is also used to ensure cooling during summer periods. On the other hand, in wet processing the major energy source is natural gas, which is mainly used for the steam production, required by the machines associated to operations such as colouring and steam ironing, as well as to provide heating of factory in winter periods.

Therefore, before any action taken towards increasing energy efficiency level of observed system, it is essential to conduct an overall site condition survey where attention should be given to identification where energy is obviously being used, or in other words, to identify spots of significant energy uses (SEUs). In order to identify SEUs, it is necessary to determine how much energy each process or system uses. In an ideal case, all large energy users will have appropriate energy sub-meters which can then be simply used to quantify the consumption of each use. In reality, few or none of energy uses will be sub-metered. In that case, their consumption should be estimated. This routine should be carried out and regularly updated for each energy source, i.e. electricity and each fuel type. However, in most cases it may be more appropriate to think in terms of processes or systems rather than pieces of equipment. Moreover, grouping equipment by energy systems (e.g. process heating, compressed air, steam systems, etc.) represents an important best practice, while understanding the dynamics of energy use in a system will lead to optimal energy savings. To achieve this, inventory and technical documentation analysis should be performed for each operation identified in Fig. 1. In addition to identified equipment energy requirements, it is also necessary to take into account other energy consuming equipment/process/system which has indirect influence on energy consumption besides manufacturing process.

\subsection{Identification of SEUs}

Given the aforementioned, a total of 490 circular knitting machines were installed in the knitting section. These machines can be divided into 9 groups while their relevant energy-related characteristics are briefly summarized in Table 1.

\begin{tabular}{|l|l|c|c|c|c|c|}
\cline { 2 - 6 } \multicolumn{1}{c|}{} & \multirow{2}{*}{ Equipment Name } & Quantity & \multicolumn{2}{c|}{ Installed power } & \multicolumn{2}{c|}{ Compressed air consumption } \\
\cline { 2 - 7 } \multicolumn{1}{c|}{} & \multicolumn{7}{|c|}{ Knitting machines } & {$[1 / \mathrm{min} / \mathrm{pcs}]$} & {$[1 / \mathrm{min}]$} \\
\hline 1 & Santoni Mirabella 2 & 40 & 1.37 & 54.8 & 195 & 7800 \\
\hline 2 & Lonati L - 301 GE & 118 & 1 & 118 & 40 & 4720 \\
\hline 3 & Lonati L-412 & 146 & 1 & 146 & 41 & 5986 \\
\hline 4 & Lonati L10P5 & 11 & 0.55 & 6.05 & 33 & 363 \\
\hline 5 & Lonati La04MJ & 10 & 0.55 & 5.5 & 33 & 330 \\
\hline 6 & Lonati L04MJ & 11 & 0.55 & 6.05 & 33 & 363 \\
\hline 7 & Lonati La10P6 & 31 & 0.55 & 17.05 & 33 & 1023 \\
\hline 8 & Lonati La10P7 & 113 & 0.55 & 62.15 & 33 & 3729 \\
\hline 9 & Lonati La24E7D & 10 & 0.55 & 5.5 & 33 & 330 \\
\hline
\end{tabular}

Table 1. Energy-related characteristics of machines associated to knitting section

Based on the data given in Table 1, total installed power of knitting machines amounts $415.05 \mathrm{~kW}$, while the maximum compressed air consumption amounts 24644 1/min. Furthermore, the sewing section include several operations such as F, PC, FS, AFS, T and S, while the typical machines and their relevant energy related characteristics are given in the Table 2. 


\begin{tabular}{|c|c|c|c|c|c|c|}
\hline & \multirow{2}{*}{ Equipment Name } & \multirow{2}{*}{$\begin{array}{c}\text { Quantity } \\
\text { [pcs] }\end{array}$} & \multicolumn{2}{|c|}{ Installed power } & \multicolumn{2}{|c|}{ Compressed air consumption } \\
\hline & & & {$[\mathrm{kW} / \mathrm{pcs}]$} & {$[\mathrm{kW}]$} & {$[1 / \mathrm{min} / \mathrm{pcs}]$} & {$[1 / \mathrm{min}]$} \\
\hline & \multicolumn{6}{|c|}{ Sewing machines } \\
\hline 1 & Speedomatic & 18 & 10 & 180 & \multirow{9}{*}{$\begin{array}{l}\text { Data are not } \\
\text { reliable }\end{array}$} & \multirow{9}{*}{$\begin{array}{c}\text { Data are no } \\
\text { reliable }\end{array}$} \\
\hline 2 & Flattlock sewing head & 20 & 0.55 & 11 & & \\
\hline 3 & Union sewing head & 8 & 0.55 & 4.4 & & \\
\hline 4 & Santoni lc320 & 2 & 3.5 & 7 & & \\
\hline 5 & Santoni lc320 + TCR & 3 & 12 & 36 & & \\
\hline 6 & Takatori lc320 & 1 & 3.7 & 3.7 & & \\
\hline 7 & Takatori lc320 + TCR & 1 & 4.5 & 4.5 & & \\
\hline 8 & Solis Turbo 11 & 1 & 5 & 5 & & \\
\hline \multirow[t]{2}{*}{9} & Solis 4C - George & 3 & 11 & 33 & & \\
\hline & \multicolumn{6}{|c|}{ Fixing machines } \\
\hline 1 & Grandis 300 (Fixer) & 1 & 7 & 7 & & \\
\hline 2 & Low capacity fixer for pads & 1 & 3 & 3 & & \\
\hline
\end{tabular}

Table 2. Energy-related characteristics of machines associated to sewing section

Sewing section with identified machines and associated operations, engages $294.6 \mathrm{~kW}$ of power. Subsequently, colouring and drying section refers to operations C, D, I and SS. Characteristic machines necessary to carry out these operations were identified and their relevant energy related properties are summarized in the Table 3.

\begin{tabular}{|c|c|c|c|c|c|c|}
\hline & \multirow{2}{*}{ Equipment Name } & \multirow{2}{*}{$\begin{array}{c}\text { Quantity } \\
\text { [pcs] }\end{array}$} & \multicolumn{2}{|c|}{ Installed power } & \multicolumn{2}{|c|}{ Water consumption } \\
\hline & & & {$[\mathrm{kW} / \mathrm{pcs}]$} & {$[\mathrm{kW}]$} & {$[1 /$ day/pcs $]$} & {$[1 /$ day $]$} \\
\hline & \multicolumn{6}{|c|}{ Coloring machines } \\
\hline 1 & Borac 1 (900 l) & 2 & 2 & 8 & 5400 & 10800 \\
\hline 2 & Borac $2(11001)$ & 2 & 5 & 10 & 6600 & 13200 \\
\hline 3 & Colori $(40-45 \mathrm{~kg})$ & 7 & 15 & 105 & 3000 & 21000 \\
\hline 4 & Colori $(1-5 \mathrm{~kg})$ & 1 & 6 & 6 & 300 & 300 \\
\hline 5 & Colori $(5-10 \mathrm{~kg})$ & 1 & 7 & 7 & 1200 & 1200 \\
\hline 6 & TEN 1 (1000 l) & 4 & 5 & 20 & 12000 & 60000 \\
\hline 7 & TEN 2 (2000 l) & 2 & 7 & 14 & 12000 & 24000 \\
\hline \multirow[t]{2}{*}{8} & TEN 3 (6000 l) & 2 & 12 & 24 & 18000 & 36000 \\
\hline & \multicolumn{6}{|c|}{ Centrifuging machines } \\
\hline 1 & Centrifuge & 2 & 15 & 30 & l & 1 \\
\hline & \multicolumn{6}{|c|}{ Drying machines } \\
\hline & \multirow{2}{*}{ Equipment Name } & Quantity & \multicolumn{2}{|c|}{ Installed power } & \multicolumn{2}{|c|}{ Steam consumption } \\
\hline & & [pcs] & {$[\mathrm{kW} / \mathrm{pcs}]$} & {$[\mathrm{kW}]$} & [t/day/pcs] & [t/day] \\
\hline 1 & Mielle 1 (electric driven) & 1 & 15 & 30 & 1 & 1 \\
\hline 2 & Mielle 2 (steam driven) & 1 & 3 & 3 & Data are not & Data are not \\
\hline 3 & Pasat (steam driven) & 2 & 3 & 9 & reliable & reliable \\
\hline \multirow[t]{2}{*}{4} & RF System & 1 & 50 & 50 & 1 & 1 \\
\hline & \multicolumn{6}{|c|}{ Ironing machines } \\
\hline 1 & Technopea SD12 & 4 & 30 & 120 & No data & No data \\
\hline 2 & Cortesse & 2 & 10 & 20 & 1 & 1 \\
\hline
\end{tabular}

Table 3. Energy-related characteristics of machines associated to coloring and drying section

Overall installed power of colouring and drying section amounts $456 \mathrm{~kW}$, which indicates that this section is the most intensive in the use of electricity. Having in mind that finishing section does not include any machine work, a more detailed analysis was not performed. However, a certain, indirect energy consumption related to FH and SR operations comes from lighting fixtures. Therefore, in the FH operation 135 fluorescent lamps are identified while their overall installed power amounts $4.86 \mathrm{~kW}$. Similarly, 90 fluorescent lamps are identified in the SR with overall installed power of $3.24 \mathrm{~kW}$.

Due to the fact that there are no reliable data regarding steam and compressed air consumption of specific operations in sewing and colouring sections, it can be assumed that the energy of steam and compressed air are not used rationally. The basis for this assumption lies in fact that the intensity of their use is not quantified or analyzed.

Beside SEUs identified in the manufacturing process, relevant spots of considerable energy uses are cooling and air conditioning system, compressor station, boiler station, lightning system, locksmith workshop, as well as office equipment. Therefore, their relevant energy-related properties are summarized in the table 4. 


\begin{tabular}{|c|c|c|c|c|}
\hline & \multirow{2}{*}{ Equipment Name } & \multirow{2}{*}{$\begin{array}{c}\text { Quantity } \\
{[\mathrm{pcs}]}\end{array}$} & \multicolumn{2}{|c|}{ Installed power } \\
\hline & & & {$[\mathrm{kW} / \mathrm{pcs}]$} & {$[\mathrm{kW}]$} \\
\hline & \multicolumn{4}{|c|}{ Cooling and air conditioning system } \\
\hline 1 & Vacuum fan (1) & 7 & 15 & 105 \\
\hline 2 & Vacuum fan (2) & 8 & 35 & 280 \\
\hline 3 & Chiller compressor & 1 & 730 & 730 \\
\hline 4 & Chiller pump & 1 & 19 & 19 \\
\hline 5 & Chiller fan & 4 & 15 & 60 \\
\hline \multirow[t]{3}{*}{6} & Industrial fan & 9 & 0.5 & 4.5 \\
\hline & \multicolumn{3}{|c|}{ Cooling and air conditioning system in total } & 1198.5 \\
\hline & \multicolumn{4}{|c|}{ Compressor and Boiler station } \\
\hline 1 & Boiler burner & 2 & 1 & 2 \\
\hline 2 & Boiler pump & 2 & 8 & 16 \\
\hline 3 & Waste press & 1 & 4 & 4 \\
\hline 4 & Compressor (1) & 2 & 132 & 264 \\
\hline 5 & Compressor (2) & 1 & 110 & 110 \\
\hline 6 & Air dryer & 1 & 20 & 20 \\
\hline 7 & Well pump (1) & 2 & 5.5 & 11 \\
\hline 8 & Well pump (2) & 2 & 1.5 & 3 \\
\hline 9 & Circulation pump (1) & 2 & 4 & 8 \\
\hline 10 & Circulation pump (2) & 1 & 5.5 & 5.5 \\
\hline \multirow[t]{3}{*}{11} & Industrial fan & 2 & 0.5 & 1 \\
\hline & \multicolumn{3}{|c|}{ Compressor and Boiler station in total } & 445.5 \\
\hline & \multicolumn{4}{|c|}{ Lighting fixtures } \\
\hline 1 & Lighting fixtures (K) & 1266 & 0.036 & 45.5 \\
\hline 2 & Lighting fixtures $(\mathrm{S})$ & 480 & 0.036 & 17.28 \\
\hline 3 & Lighting fixtures $(\mathrm{C})$ & 130 & 0.036 & 4.68 \\
\hline 4 & Lighting fixtures $(\mathrm{FH})$ & 135 & 0.036 & 4.86 \\
\hline 5 & Lighting fixtures (SR) & 90 & 0.036 & 3.24 \\
\hline 6 & Lighting fixtures (Office) & 50 & 0.036 & 1.8 \\
\hline \multirow[t]{3}{*}{7} & Lighting fixtures (Other) & 30 & 0.036 & 1.08 \\
\hline & \multicolumn{3}{|l|}{ Lighting fixtures in total } & 78.44 \\
\hline & \multicolumn{4}{|c|}{ Locksmith workshop } \\
\hline 1 & Milling machine & 1 & 1.1 & 1.1 \\
\hline 2 & Lathe (1) & 1 & 2.5 & 2.5 \\
\hline 3 & Lathe (2) & 1 & 4 & 4 \\
\hline 4 & Drill & 2 & 1.5 & 3 \\
\hline 5 & Welding machine (1) & 1 & 2.5 & 2.5 \\
\hline 6 & Welding machine (2) & 1 & 2 & 2 \\
\hline 7 & Rendering machine & 1 & 2.5 & 2.5 \\
\hline 8 & Grinding machine & 1 & 2 & 2 \\
\hline 9 & Grinding stone & 1 & 1 & 1 \\
\hline \multirow[t]{3}{*}{10} & Frame saw & 1 & 1 & 1 \\
\hline & \multicolumn{3}{|l|}{ Locksmith workshop in total } & 23.6 \\
\hline & \multicolumn{4}{|c|}{ Office equipment } \\
\hline 1 & Air conditioner (1) & 6 & 2.8 & 16.8 \\
\hline 2 & Air conditioner (2) & 2 & 3.4 & 6.8 \\
\hline 3 & Water heater (1) & 8 & 2.5 & 20 \\
\hline 4 & Water heater (2) & 2 & 10 & 20 \\
\hline \multirow[t]{2}{*}{5} & Desktop computers & 37 & 0.4 & 14.8 \\
\hline & \multicolumn{3}{|l|}{ Office equipment in total } & 78.4 \\
\hline
\end{tabular}

Table 4. Relevant energy-related properties of processes and systems indirectly linked to manufacturing

Bearing in mind the given data (Tables 1-4), SEUs and their share in overall electricity consumption depending on the engaged power were identified and illustratively given in the form of pie chart (Fig. 3). Here, the cooling and air condition systems represent most intensive electricity consumers with a share of $40 \%$. In addition, manufacturing participates with a share of 39\%, where most energy demanding sections are colouring and drying (39\%), followed by knitting (36\%) and sewing (25\%) section respectively. Subsequently, compressor and boiler station are characterized by 
a share of $15 \%$, while the least energy demanding SEUs identified are lightning fixtures (3\%), office equipment (2\%) and locksmith workshop (1\%).

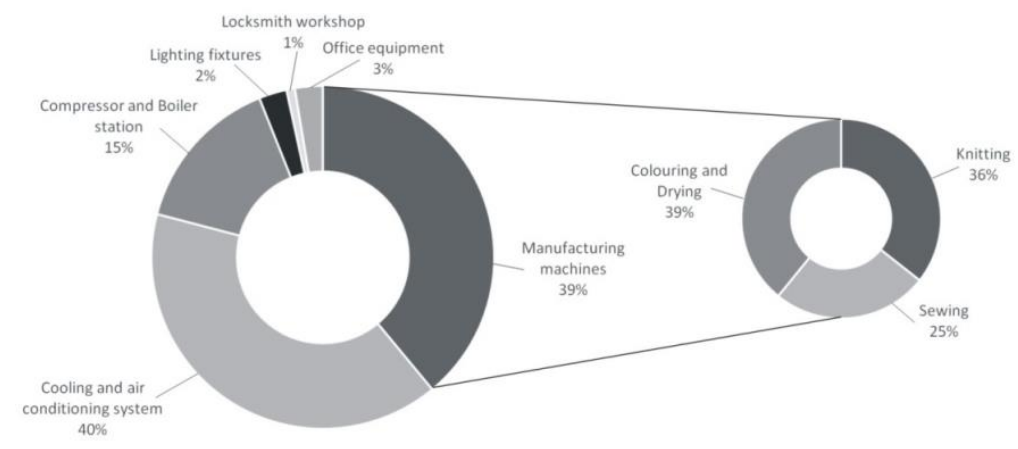

Fig. 3. Identified SEUs and their share in overall electricity consumption depending on the engaged power

\subsection{Determination of energy efficiency potential in socks manufacturing}

Accurate determination or measurement of energy consumption and industrial energy efficiency projects as well, can reduce uncertainty and stimulate development and implementation of future projects, while generating more reliable and more accurate estimations of expected savings, which finally lead to improved utilization of capital resources. Moreover, many efforts to determine industrial energy saving potential, or simply track progress toward efficiency goals, have had difficulty incorporating weather and production changes, which are frequently major drivers of energy use in majority of manufacturing systems. As the energy use often represents a function of weather and/or production, which frequently changes between the pre and post retrofit period, it is more difficult to measure energy savings and, as a consequence, savings are verified sparsely. This lack of verification hurts the effort to maximize industrial energy efficiency. In some cases, retrofit measures which would realize the expected savings are not implemented since there is no history of successful verification. In other cases, retrofits that do not achieve the expected savings get implemented, which wastes resources that may have been allocated to more effective measures. Both of these problems could be minimized by measuring savings systematically in order to compare expected and measured savings, where the adequate information could guide the selection of future retrofits, improvement of methods to calculate expected savings, promotion of financing energy efficiency through shared-savings agreements and utilization of resources [12].

Having this and all previously mentioned in mind, in this paper a general method for industrial energy efficiency potential determination was presented. At the very beginning, it is of high importance to establish the crucial physical components or subsystems for both energy and production that play a key role in the supply and demand side of overall process operation. In other words, when energy and process flow charts are put together, valuable information are provided on where, why and what type of energy is used. This represents the basis for decisions on identifying and determination of relevant measuring spots in order to monitor the process towards to energy efficiency and rational energy use [13]. Having this in mind, figure 4 illustrates the scope of this research as correlation between energy consumption and manufacturing process or other relevant energy consuming system in the observed factory. Thereafter, beside to the only 2 , legally binding, measuring points, 30 potential measuring spots were identified. More precisely, 17 power, 5 steam flow, 7 air flow and a water flow data logging spots were suggested in order to monitor relevant parameters causing energy consumption. Subsequently, it is necessary to understand trends in energy consumption and in potentially relevant variables. After visibly assessing aforementioned, the significance of the relationship could be accessed by correlation of specific variables against energy consumption using a simple X-Y diagram. Here, if the variable is relevant, one expects to see evidence of a relationship in the scatter of points. In other words, if the points appear to be scattered around a mathematical function, shown as a trend line then this is indicative of the presence of relevant variables. Otherwise, if the points appear as a random cloud with no evident relationship, the variable is likely not relevant. Based on the above, the figure 5 illustrates correlation between total energy consumption reduced to $\mathrm{kWh}$ and production volume (left), as well as correlation between solely electricity consumption and production volume (right) in the observed factory. Similarly, figure 6 provides an overview regarding the correlation strength between natural gas consumption and production volume. Having in mind that the coefficient of determination $\left(\mathrm{R}^{2}\right)$ explains how many points fall on the regression line, it represents a measure of the goodness how trend line fits to the data, where a value of 1 indicates an ideal case, or a perfect fit respectively. In all three cases given in the figures 5 and $6, \mathrm{R}^{2}$ value does not exceed 0.31 indicating a very week correlation between energy consumption and production volume. More precisely, $\mathrm{R}^{2}$ values of $0.31,0.29$ and 0.21 indicate that only $31 \%, 29 \%$ and $21 \%$ fits to the data from which it can be concluded that energy consumption does not depend on production. However, it is important to accentuate that when production volume is equalled to 0 , baseload total energy consumption amounts 697.2 MWh/month. Of this $697.2 \mathrm{MWh} / \mathrm{month}$, $393.64 \mathrm{MWh} / \mathrm{month}$ represent electricity consumption, while $303.55 \mathrm{MWh} /$ month $\left(41411.13 \mathrm{~m}^{3} / \mathrm{month}\right)$ is consumed as natural gas. The ways the points appear as a random cloud with no evident relationship indicate a potential for energy efficiency improvement of observed manufacturing system. 


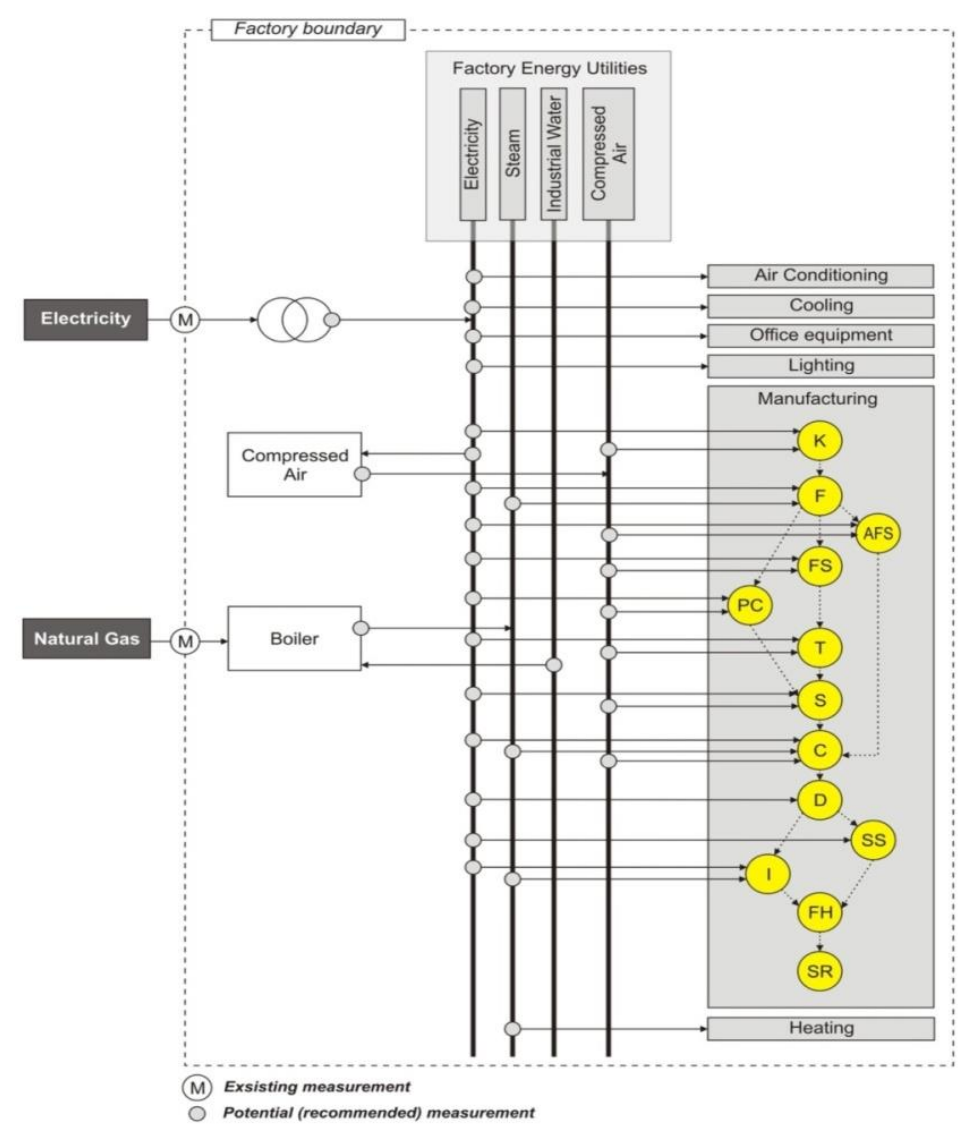

Fig. 4. Process and energy flow chart of a socks manufacturing factory with present and recommended measuring spots
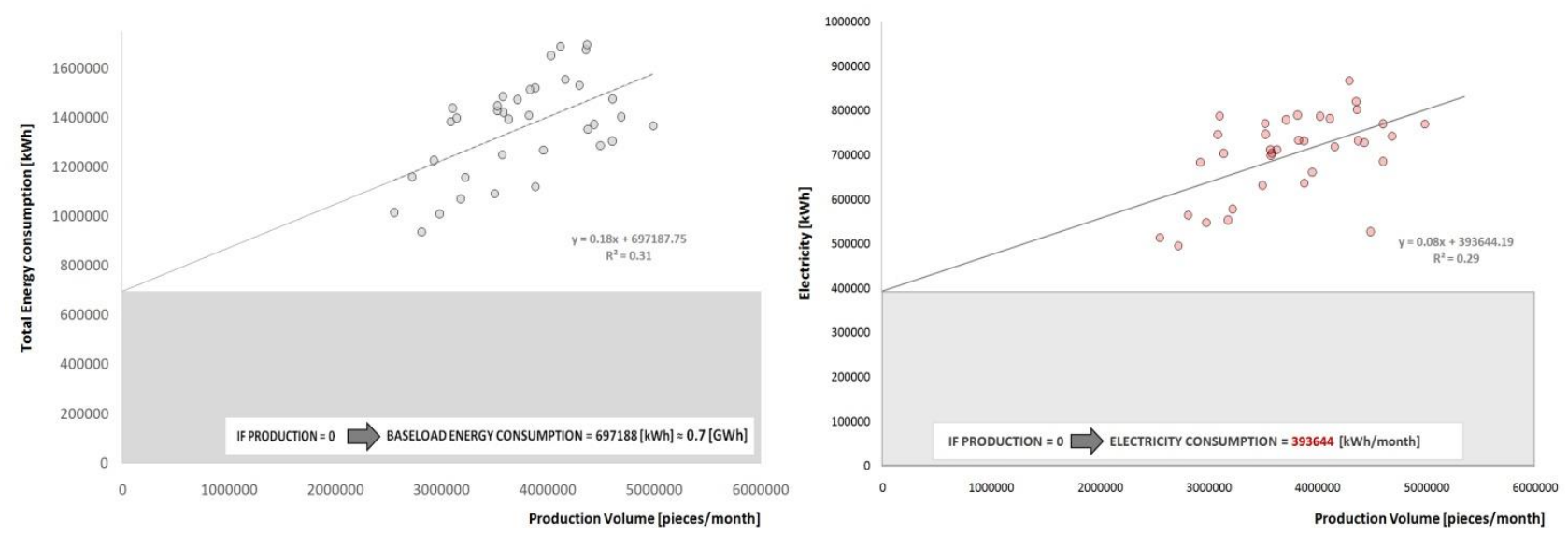

Fig. 5. Correlation between energy consumption and production volume in the observed factory

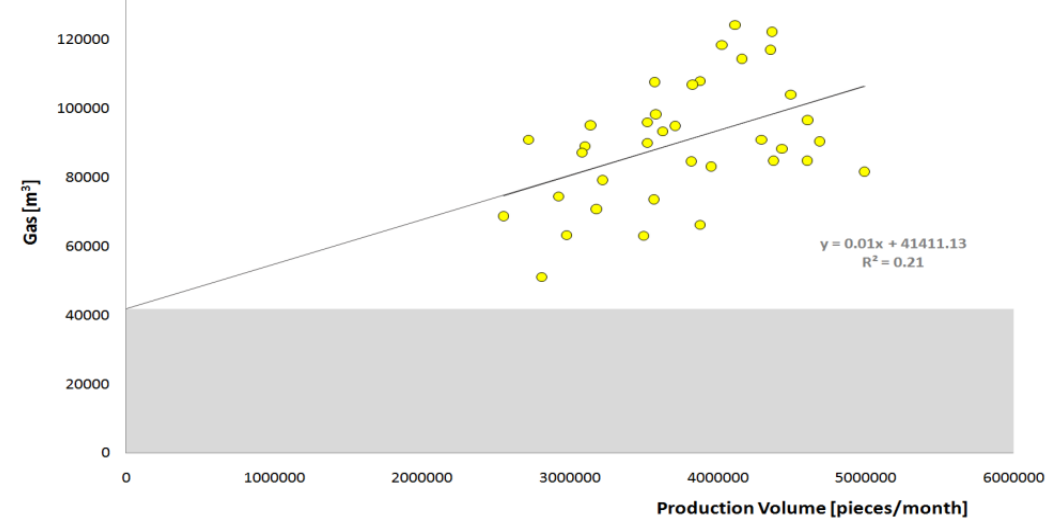

Fig. 6. Correlation between natural gas consumption and production volume in the observed factory 
Subsequently, a variety of models and statistical methods can be used to describe energy use in manufacturing systems. For example, neural network models can accurately capture non-linear relationships and cross correlation among multiple independent variables, while Principal component analysis could be used to handle multi co-linearity associated with time series data. In addition, other examples of empirical modelling of industrial energy use introduced a productivity index to understand productivity, efficiency and environmental performance [12]. Although these methods all have appropriate applications, a multivariable regression modelling technique is chosen to identify segments for best practices application. Here, a general multivariable regression method for measuring industrial energy efficiency potential that takes into account changes in weather (through Heating degree days (HDD) and Cooling Degree Days (CDD)) and production was applied while the obtained results are given in the table 5.

\begin{tabular}{|c|c|c|c|c|c|c|}
\hline \multicolumn{2}{|c|}{ Regression Statistics } & \multicolumn{3}{|c|}{ ANOVA Regression } & & \\
\hline Multiple R & 0.75 & $d f$ & \multicolumn{2}{|c|}{3} & & \\
\hline R Square & 0.57 & $S S$ & \multicolumn{2}{|c|}{$5.74 \mathrm{e}^{11}$} & & \\
\hline Adjusted R Square & 0.50 & $M S$ & \multicolumn{2}{|c|}{$1.91 \mathrm{e}^{11}$} & & \\
\hline Standard Error & 148213 & $F$ & \multicolumn{2}{|l|}{8.71} & & \\
\hline Observations & 24 & Significance $F$ & \multicolumn{2}{|c|}{0.000675} & & \\
\hline \multicolumn{7}{|c|}{ Interpret regression coefficients } \\
\hline & Coefficients & Standard Error & $t$ Stat & $P$-value & Lower 95\% & Upper 95\% \\
\hline Intercept & 447266.99 & 209036.81 & 2.14 & 0.045 & 11223.84 & 883310.14 \\
\hline Production volume & 0.19 & 0.049 & 3.86 & 0.00098 & 0.088 & 0.29 \\
\hline HDD & 661.3 & 299.16 & 2.21 & 0.039 & 37.27 & 1285.32 \\
\hline CDD & 511.11 & 523.51 & 0.98 & 0.34 & -580.92 & 1603.14 \\
\hline
\end{tabular}

Table 5. Results of multivariable regression analysis

\section{Discussion and results interpretation}

The Regression analysis is carried out in order to determine the coefficients that yield the smallest residual sum of squares, which is equivalent to the greatest correlation coefficient squared. Moreover, the ANOVA probability (Significance F) that generated equation does not explain the variation in y, i.e. that any fit is purely by chance amounts 0.000675 indicating a quite meaningful correlation based on the F probability distribution. Also, the probability that the true value of the coefficient has the opposite sign to that found (P-value) suggests that variables in terms of production volume and HDD really influence energy consumption in the observed factory, which is not the case for CDD. In other words, this means that significant potential for energy efficiency improvement lies in the cooling and air condition systems retrofitting, which at the same time represent the most significant SEU. Thereafter, a $95 \%$ probability, that the true value of the coefficient, lies between the Lower 95\% and Upper 95\% values in the section of interpret regression coefficients (Table 5.). This probability is $2.5 \%$ that it lies in below the lower value, and $2.5 \%$ that it lies above. In addition to statistically verified data, a reduction of $30 \%$ in energy consumption is typical and achievable by improving operation control in managing compressed air system (CAS) in the observed factory by identifying and repairing air leaks, measuring and baselining CAS to determine the operating costs and efficiency or operating compressed air system at the lowest practical pressure. Also, other highly effective practical recommendations suggest installation, adjustment and maintenance of automatic system controls to coordinate operations of air compressors, cutting of compressed air supply to zones, equipment and applications that are not operating, using a blower rather than a compressor where and when appropriate, implementation of air reservoirs to reduce compressor cycling and respond to peak air demands, etc [14]. Beside CAS optimization, huge potential for improving energy efficiency was found in colouring and drying section of manufacturing where on daily basis 166.5 tons of hot water $\left(98^{\circ} \mathrm{C}\right)$ is being released into the sink. By implementing an adequate system of heat exchangers in order to recover heat from the fleet which is being released to sink to preheat the water entering the steam generation boiler to the temperature of only $40^{\circ} \mathrm{C}$, additional $30 \%$ reduction could be achieved in the natural gas consumption for steam generation. Lastly, although this method seeks to extract as much information about savings as possible from easily obtainable utility billing, production and temperature data, the extractable information is limited by the information in the data set, which is sparse in the both the system and time domain. This emphasizes the need for data logging at recommended measuring spots identified in the figure 4 .

\section{Conclusion}

In this study, a straightforward structured framework has been proposed and applied to determine energy efficiency potential of a socks manufacturing system. The methodology has been illustrated through a concrete case in the example of an energy intensive branch of textile industry. The energy efficiency potential in whole energy system of a factory has been assessed through a statistical and deterministic approach.

Given the aforementioned, several limitations regarding the applied approach should be taken into account. Firstly, due to a variety and complexity of the processes involved in the socks manufacturing process, there are too many operations to be explained. Therefore, only the major processes and operations relevant from the energy consumption 
point of view were subjected to analysis. In addition, although in most cases it may be more appropriate to think in terms of processes or systems rather than pieces of equipment, grouping equipment by energy systems (e.g. process heating, compressed air, steam systems, etc.) represents an important best practice, where understanding the dynamics of energy use in a system could lead to optimal energy savings. Here, it is hard to understand the dynamics of energy use if not tracking the relevant changes over time, which points to the next important limitation, which is time awareness. It is important to simultaneously be aware when, where, why and what type of energy is used in order to make the best possible decision regarding improving productivity through fostering energy efficiency. Consequently, ensuring basic measurements in production segments where activities or production volume are quantifiable and where a significant amount of energy is used, valuable information are provided to understand the dynamics of energy use. Subsequently, the last limitation refers to statistical approach based on general multivariable regression method itself, due to the fact that, although the main drivers of energy consumption, only changes in weather and production were variables considered in this study. Also, even though this statistical approach indicates energy efficiency potential, it does not provide explanation what should be done to improve efficiency. However, it is believed that integration of other variables could provide clearer overview on how energy is actually being used up on which relevant energy flows could be identified and monitored carefully. Lastly, the methodology presented in this paper consists of a wide set of tools for energy management, which can be implemented within the systematic framework in order to reveal the energy efficiency potential necessary to foster the rational energy utilization in the observed manufacturing system, while plans for future research in this field are aimed to complement this methodology by revealing and understanding potential limitations, which are not identified at present. On top of that, the case study presented in this paper refers to single product processes, while the same methodology could be applied for multiple product processes, where it is more complex to comprehend how energy is provided and finally how energy consumptions allocation is stipulated among them.

\section{References}

[1] Hasanbeigi, A., Price, L. (2012). "A review of energy use and energy efficiency technologies for the textile industry”, Renewable \& Sustainable Energy Reviews., Vol. 16, No. 6, pp. 3648-3665, ISSN: 1364-0321.

[2] Gielen, D., Taylor, P. (2009). "Indicators for industrial energy efficiency in India", Energy, Vol. 34, No. 8, pp. 962969, ISSN: 0360-5442.

[3] Palamutcu, S. (2010). "Electric energy consumption in the cotton textile processing stages," Energy, Vol. 35, No. 7, pp. 2945-2952, ISSN: 0360-5442.

[4] Ramirez, C., Patel, M., Blok, K. (2006). "From fluid milk to milk powder: Energy use and energy efficiency in the European dairy industry”, Energy, Vol. 31, No. 12, pp. 1984-2004, ISSN: 0360-5442.

[5] Xu, T., Flapper, J., Kramer, K. J. (2009). "Characterization of energy use and performance of global cheese processing”, Energy, Vol. 34, No. 11, pp. 1993-2000, ISSN: 0360-5442.

[6] Salta, M., Polatidis, H., Haralambopoulos, D. (2009). "Energy use in the Greek manufacturing sector: A methodological framework based on physical indicators with aggregation and decomposition analysis", Energy, Vol. 34, No. 1, pp. 90-111, ISSN: 0360-5442.

[7] "Reference Document on Best Available Techniques for Energy Efficiency," 2009. Available at: http://eippcb.jrc.ec.europa.eu/reference/BREF/ENE_Adopted_02-2009.pdf

[8] Siitonen, S., Tuomaala, M., Ahtila, P. (2010). "Variables affecting energy efficiency and $\mathrm{CO}_{2}$ emissions in the steel industry," Energy Policy, Vol. 38, No. 5, pp. 2477-2485, ISSN: 0301-4215.

[9] Patterson, M. G. (1996). “What is energy efficiency?”, Energy Policy, Vol. 24, No. 5, pp. 377-390, ISSN: 03014215.

[10] Tanaka, K. (2008).“Assessment of energy efficiency performance measures in industry and their application for policy,” Energy Policy, Vol. 36, No. 8, pp. 2887-2902, ISSN: 0301-4215.

[11]Bunse, K., Vodicka, M., Schönsleben, P., Brülhart, M., Ernst, F. O. (2011). "Integrating energy efficiency performance in production management - gap analysis between industrial needs and scientific literature," Journal of Cleaner Production, Vol. 19, No. 6-7, pp. 667-679, ISSN: 0959-6526.

[12] Kissock, J.K., Eger, C. (2008). "Measuring industrial energy savings”, Applied Energy, Vol. 85, pp. 347-361, ISSN: 0306-2619.

[13] Medojevic, M., Cosic, I., Sremcev, N., \& Lazarevic, M. (2016). "Conceptual Theoretical Model for Life Cycle Energy Analysis of Photovoltaic Modules", Proceedings of the $27^{\text {th }}$ DAAAM International Symposium, pp.0534 0543, B. Katalinic (Ed.), Published by DAAAM International, ISBN 978-3-902734-08-2, ISSN 1726-9679, Vienna, Austria DOI: $10.2507 / 27$ th.daaam.proceedings.079

[14] Medojevic, M. (2016). "Analysis of Current Automation Level in Specific Compressed Air System with Model for Optimization", Proceedings of the $26^{\text {th }}$ DAAAM International Symposium, pp.1082-1090, B. Katalinic (Ed.), Published by DAAAM International, ISBN 978-3-902734-07-5, ISSN 1726-9679, Vienna, Austria DOI: 10.2507/26th.daaam.proceedings. 152 